
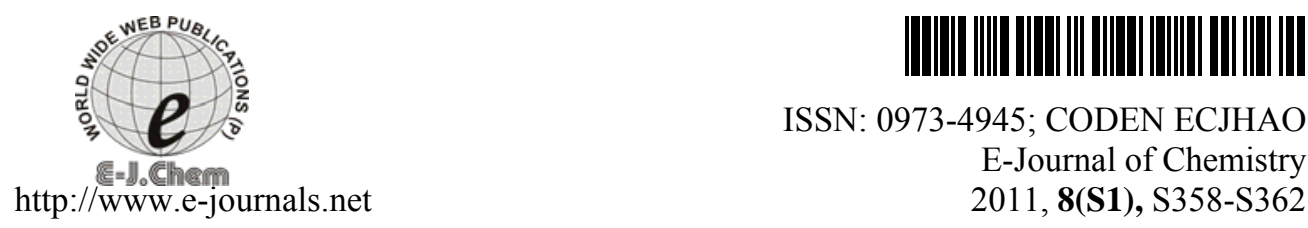

ISSN: 0973-4945; CODEN ECJHAO

E-Journal of Chemistry

http://www.e-journals.net

2011, 8(S1), S358-S362

\title{
Study on the Corrosion Kinetics of Iron in Acid and Base Medium
}

\author{
D.B. PATIL ${ }^{*}$ and A.R. SHARMA \\ *Department of Chemistry \\ Institute of Science, Nagpur - 440 001, India \\ Department of Chemistry \\ Manoharbhai Patel Institute of Engineering and Technology \\ Gondia - 441 614, India \\ anupsharma123@rediffmail.com
}

Received 24 January 2011; Accepted 12 April 2011

\begin{abstract}
The kinetics of corrosion of iron in acid and base medium by weight loss method was investigated. The corrosion kinetics was studied in sulphuric acid, nitric acid and potassium hydroxide by weight loss method at different time intervals at $25.0^{\circ} \mathrm{C}$ to $40.0^{\circ} \mathrm{C}$. The result showed that the corrosion rate vary with different time interval and different acid - base concentration. The order of corrosion of iron in these media was found to be nitric acid $>$ sulphuric acid $>$ potassium hydroxide. Further the specific reaction rate, halflife time, energy of activation, entropy of activation and enthalpy of activation was also evaluated.
\end{abstract}

Keywords: Iron, Corrosion, Weight loss method, Acid- base medium

\section{Introduction}

Iron is widely used in many industries. During industrial process such as pickling, etching, acid cleaning, acid de-scaling, iron is often made to come in contact with aggressive solutions such as acidic and basic solutiions ${ }^{1-4}$. Hence metal is prone to corrosion attack. The magnitude of corrosion of metal depends on the concentration of acidic and basic medium, operating temperature and period of contact $e t c^{5-6}$. Various workers have explained the interaction of these medium on the surface of iron $^{7-12}$.

This study assesses the corrosion of iron in sulphuric acid, nitric acid and potassium hydroxide medium using weight loss method. Comparative corroding behaviour, kinetics and activating parameters are explained.

\section{Experimental}

Iron sheet (Jindal Iron Limited, India) were purchased from local market and specimen of $5 \mathrm{~cm} \times 5 \mathrm{~cm}$ were prepared for weight loss measurements. All the specimen surfaces were 
polished with emery paper and then dipped into 1:1 hydrochloric acid solution for $15 \mathrm{~min}$. They were washed first with tap water and with double distilled water, dried in air and then washed with acetone. All specimens dried in hot air and weighed on analytical balance to an accuracy of $5 \%$. The weight of specimen were noted and then dipped into test solution of acids and base at $25.0^{\circ} \mathrm{C}$. At regular time intervals (up to 60 minutes), the specimen were removed from the test solution and washed with tap, double distilled water, dried in air, washed with acetone and again dried in hot air. Finally the weights recorded. The differences in weights at each interval were noted and the corrosion rates and specific reaction rates were calculated.

\section{Solutions}

All the chemicals used in the present investigation, for the preparation of solutions were of analytical grade. Glass doubly distilled water was for the preparation of all the solutions.

\section{Results and Discussion}

\section{Corrosion of iron}

The corrosion rate of iron in different concentrations of sulphuric acid ranging from $0.5 \mathrm{~N}$ to $3 \mathrm{~N}$ for exposure time of 60 minutes has been determined by weight loss method at $25.0{ }^{\circ} \mathrm{C}$ to $40.0{ }^{\circ} \mathrm{C}$. It is observed that iron corrodes in different concentration of sulphuric acid because there is considerable decrease in original weight of the specimen. The corrosion is due to water, air and hydrogen ion, which enhance the corrosion process. The corrosion takes place at the surface of iron, which is a reaction site. Figure 1 show that the corrosion rate increased with increase in concentration of sulphuric acid and time. Similar results were obtained in case of nitric acid (Figure 2). However the weight loss was more pronounced in nitric acid as compared to sulphuric acid. This may be due to powerful oxidizing action of nitric acid which causes violent attack on Iron.

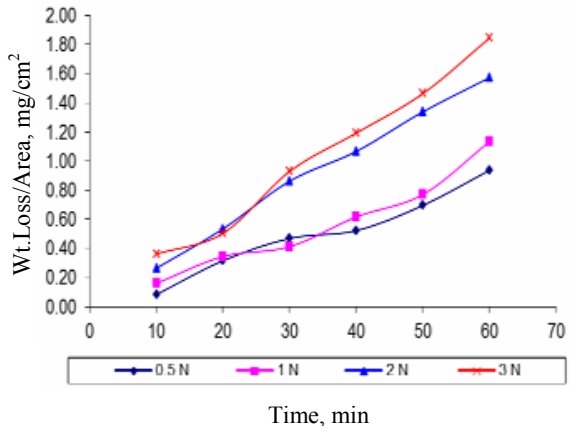

Figure 1. Effect of concentration of sulphuric acid on corrosion rate.

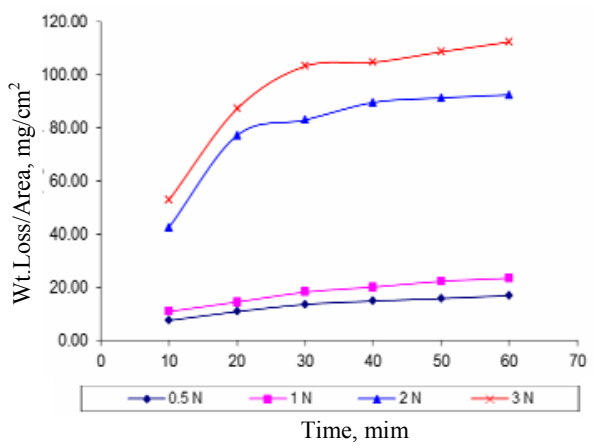

Figure 2. Effect of concentration of nitric acid on corrosion rate.

The study of corrosion of iron in potassium hydroxide $(1.0 \mathrm{~N}$ to $4.0 \mathrm{~N})$ for 200 minutes at $30{ }^{\circ} \mathrm{C}$ to $60.0^{\circ} \mathrm{C}$ showed that iron corrodes in these concentrations. As the concentration of potassium hydroxide increases the weight loss decreases (Figure 3). This is attributed to the fact that initially there is formation of ferric hydroxide layer. As concentration increases there will be protective layer of ferric hydroxide on the surface of iron specimen, which decreases the weight loss. 


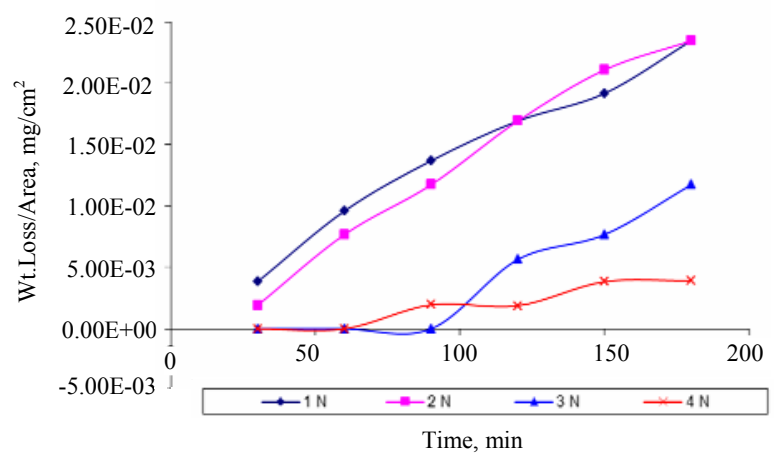

Figure 3. Effect of concentration of potassium hydroxide on corrosion rate

\section{Effect of temperature}

Figure 4 shows that there is progressive increase in weight loss as the temperature increased from $25.0{ }^{\circ} \mathrm{C}$ to $40.0{ }^{\circ} \mathrm{C}$. This indicates that corrosion of iron in sulphuric acid increases at higher temperature, which is according to principles of chemical kinetics. The increase in weight loss may also be due to diffusion and ionization of reactants or due to increase in solubility of protective layer, which makes surface susceptible for corrosion.

Similar trend was observed in case of nitric acid but weight loss was more as compared to sulphuric acid (Figure 5). In case of potassium hydroxide as corrodent, at $30{ }^{\circ} \mathrm{C}$ the weight loss increases with immersion time. Further increase in temperature decreases the weight loss and then after there is progressive increase in weight loss from $40{ }^{\circ} \mathrm{C}$ to $60{ }^{\circ} \mathrm{C}$ (Figure 6). The decrease in weight loss from $30{ }^{\circ} \mathrm{C}$ to $40{ }^{\circ} \mathrm{C}$ may be due to formation of ferric hydroxide layer on the surface of iron which further dissolves as the temperature increases from $40{ }^{\circ} \mathrm{C}$ to $60{ }^{\circ} \mathrm{C}$. By dissolution of ferric hydroxide layer again the iron surface is open for corrrodent.

\section{Kinetic study}

The initial weight of iron specimen and change in weight of specimen at various instant of time in sulphuric acid were calculated. From these values, the specific reaction rate values were calculated using first order rate expression, $\mathrm{k}=(2.303 / \mathrm{t}) \log$ ([Initial wt. of specimen]/[wt. at time, $\mathrm{t}]$ ).

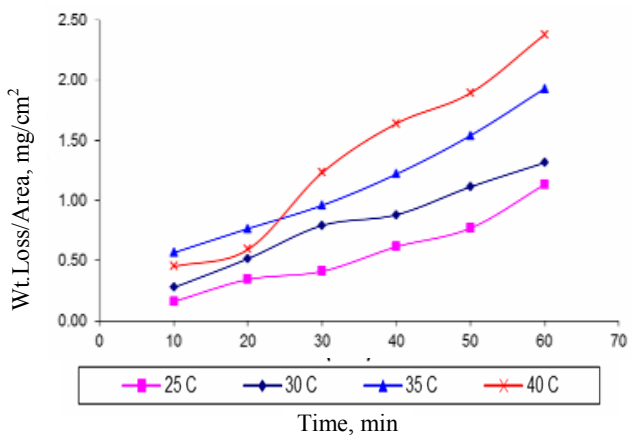

Figure 4. Effect of temperature on corrosion rate in sulphuric acid

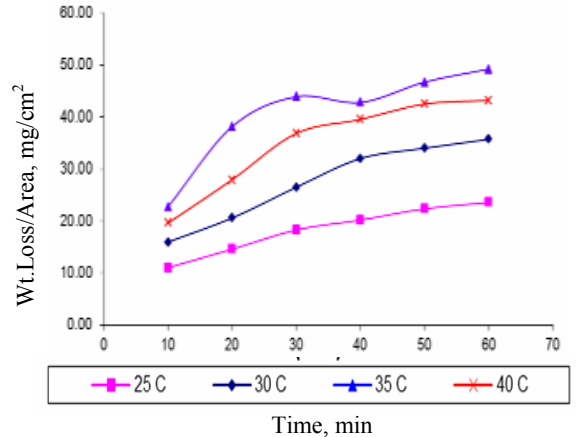

Figure 5. Effect of temperature on corrosion rate in nitric acid 


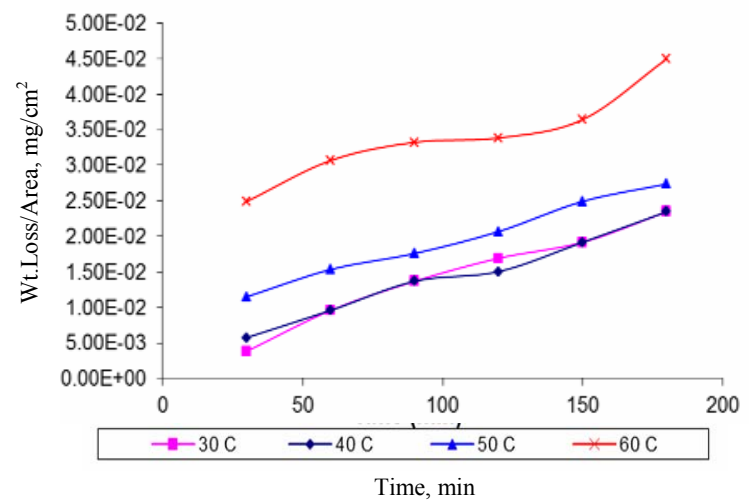

Figure 6. Effect of temperature on corrosion rate in potassium hydroxide

The half - life time values were calculated by formula $t_{1 / 2}=0.693 / \mathrm{k}$. It was observed that specific reaction rate, $\mathrm{k}$ increases with increase in temperature from $25{ }^{\circ} \mathrm{C}$ to $40{ }^{\circ} \mathrm{C}$ and corresponding decrease in half - life time takes place (Table 1). It confirms the first order kinetics for the corrosion of iron in sulphuric acid.

Table 1. Effect of temperature on corrosion rate in sulphuric acid

\begin{tabular}{|c|c|c|c|c|c|}
\hline \multicolumn{2}{|c|}{$\begin{array}{l}\text { Size of Iron coupon } \\
\text { Concentration of } \mathrm{H}_{2} \mathrm{SO}_{4} \\
\text { Volume of } \mathrm{H}_{2} \mathrm{SO}_{4}\end{array}$} & \multicolumn{4}{|l|}{$\begin{array}{l}: 5 \times 5 \mathrm{~cm}^{2} \\
: 1 \mathrm{~N} \\
: 150 \mathrm{~cm}^{3}\end{array}$} \\
\hline $\mathrm{S}$ & Temp. & Specific Reaction & Half Life & $\begin{array}{l}\text { Energy of } \\
\text { Activation }\end{array}$ & $\begin{array}{c}\text { Average } \\
\mathrm{E}_{\mathrm{a}}{ }^{*}\end{array}$ \\
\hline No. & ${ }^{\circ} \mathrm{C}$ & Rate, $\mathrm{k} / 10^{-4} \mathrm{~min}^{-1}$ & $\mathrm{t}_{1 / 2} / 10^{3}$ & $\mathrm{E}_{\mathrm{a}}{ }^{*} \mathrm{kJmole}^{-1}$ & $\mathrm{kJmole}^{-1}$ \\
\hline 1 & 25 & 0.79 & 8.68 & - & \\
\hline 2 & 30 & 1.23 & 5.63 & 64.9601 & 46.9231 \\
\hline 3 & 35 & 1.86 & 3.73 & 64.1762 & \\
\hline 4 & 40 & 2.00 & 3.47 & 11.6331 & \\
\hline
\end{tabular}

Similar specific reaction rate, $\mathrm{k}$ and half - life time values were calculated for the corrosion of Iron in nitric acid and potassium hydroxide solution. Surprisingly in both the corrodent, corrosion shows first order kinetics (Table 2 and Table 3).

Table 2. Effect of temperature on corrosion rate in nitric acid

\begin{tabular}{|c|c|c|c|c|c|}
\hline \multicolumn{2}{|c|}{$\begin{array}{l}\text { Size of Iron coupon } \\
\text { Concentration of } \mathrm{HNO}_{3} \\
\text { Volume of } \mathrm{HNO}_{3}\end{array}$} & \multicolumn{4}{|l|}{$\begin{array}{l}: 5 \times 5 \mathrm{~cm}^{2} \\
: 1 \mathrm{~N} \\
: 150 \mathrm{~cm}^{3}\end{array}$} \\
\hline S. & Temp. & Specific Reaction & Half Life & $\begin{array}{l}\text { Energy of } \\
\text { Activation }\end{array}$ & $\begin{array}{c}\text { Average } \\
\mathrm{E}_{\mathrm{a}}^{*}\end{array}$ \\
\hline No. & ${ }^{\circ} \mathrm{C}$ & Rate, $\mathrm{k} / 10^{-3} \mathrm{~min}^{-1}$ & $t_{1 / 2} / 10^{2}$ & $\mathrm{E}_{\mathrm{a}}^{*} \mathrm{kJmole}^{-1}$ & $\mathrm{kJmole}^{-1}$ \\
\hline 1 & 25 & 6.00 & 1.16 & - & \\
\hline 2 & 30 & 6.33 & 1.09 & 8.0387 & 12.6415 \\
\hline 3 & 35 & 6.40 & 1.08 & 1.7066 & \\
\hline 4 & 40 & 7.63 & 9.08 & 28.1792 & \\
\hline
\end{tabular}


Table 3. Effect of temperature on corrosion rate in potassium hydroxide

\begin{tabular}{|c|c|c|c|c|c|}
\hline \multicolumn{2}{|c|}{$\begin{array}{l}\text { Size of Iron coupon } \\
\text { Concentration of } \mathrm{KOH} \\
\text { Volume of } \mathrm{KOH}\end{array}$} & \multicolumn{4}{|l|}{$\begin{array}{l}: 5 \times 5 \mathrm{~cm}^{2} \\
: 1 \mathrm{~N} \\
: 150 \mathrm{~cm}^{3}\end{array}$} \\
\hline S. & Temp. & Specific Reaction & Half Life & $\begin{array}{l}\text { Energy of } \\
\text { Activation }\end{array}$ & $\begin{array}{c}\text { Average } \\
\mathrm{E}_{\mathrm{a}}^{*}\end{array}$ \\
\hline No. & ${ }^{\circ} \mathrm{C}$ & Rate, $\mathrm{k} / 10^{-6} \mathrm{~min}^{-1}$ & $\mathrm{t}_{1 / 2} / 10^{6}$ & $\mathrm{E}_{\mathrm{a}}^{*} \mathrm{kJmole}^{-1}$ & $\mathrm{kJmole}^{-1}$ \\
\hline 1 & 30 & 0.68 & 1.02 & - & \\
\hline 2 & 40 & 0.72 & 0.96 & 4.6032 & 31.7358 \\
\hline 3 & 50 & 1.08 & 0.64 & 33.7314 & \\
\hline 4 & 60 & 2.04 & 0.34 & 56.8730 & \\
\hline
\end{tabular}

The energy of activation, Ea, for the corrosion of iron in sulphuric acid, nitric acid and potassium hydroxide was evaluated by determining specific reaction rates at temperatures range $25^{\circ} \mathrm{C}$ to $40{ }^{\circ} \mathrm{C}$ and $30{ }^{\circ} \mathrm{C}$ to $60^{\circ} \mathrm{C}$ respectively. The Arrhenius equation, $\mathrm{k}=\mathrm{A} \mathrm{e} \mathrm{e}^{-\mathrm{Ea} / \mathrm{RT}}$ was used to evaluate energy of activation values. The entropy of activation, $\Delta \mathrm{S}^{*}$ and enthalpy of activation, $\Delta \mathrm{H}^{*}$ were calculated using transition state equation: $\mathrm{K}=\mathrm{RT} / \mathrm{Nh} \cdot \mathrm{e}^{\Delta \mathrm{S}^{* / \mathrm{R}}} \cdot \mathrm{e}^{-\Delta \mathrm{H}^{* / R T}}$ (Table. 4).

Table 4. Kinetics of corrosion of Iron: activation parameters

\begin{tabular}{|c|c|c|c|c|}
\hline S. No. & Activation Parameters & $\mathrm{H}_{2} \mathrm{SO}_{4}$ & $\mathrm{HNO}_{3}$ & $\mathrm{KOH}$ \\
\hline 1 & $\begin{array}{l}\text { Energy of activation, } \\
\mathrm{E}_{\mathrm{a}}^{*}\left(\mathrm{~kJ} \mathrm{~mole}^{-1}\right)\end{array}$ & 46.92 & 12.64 & 31.74 \\
\hline 2 & $\begin{array}{l}\text { Entropy of activation, } \\
\Delta \mathrm{S}^{*}\left(\mathrm{~J} \text { mole }{ }^{-1} \mathrm{~K}^{-1}\right)\end{array}$ & -165.93 & -245.06 & -191.61 \\
\hline 3 & $\begin{array}{l}\text { Enthalpy of activation, } \\
\Delta \mathrm{H}^{*}\left(\mathrm{~kJ} \mathrm{~mole}^{-1}\right)\end{array}$ & 44.42 & 10.14 & 29.24 \\
\hline
\end{tabular}

\section{References}

1. Desai M N and Desai M B, Corros Sci., 1984, 24(8), 649-660.

2. Sazou D, Georgolios C and Pagitsas M, Electrochemica Acta, 1993, 38, 2321.

3. Snarely E S and Hackerman N, NACE, Basic Corrosion Course, NACE, Houston 1970.

4. Noor E A, Corros Sci., 2005, 33, 47.

5. Mathiyarasu J, Nehru I C, Subramania P, Palaniswamy N and, Rangaswamy N S, Anticorrosion Methods Materials, 2001, 48(5), 324-329.

6. Ochao N, Moran F and Pebre N, J Appl Electrochem., 2004, 34, 487.

7. Oguzie E E, Unaegbu C, ogukwe C N, Okoule B N and Onuchukwu A J, Mater Chem Phys., 2004, 84, 363.

8. Rajendran S, Maria Joany R, Apparao B V and Palaniswamy N, Trans SAEST, 2000, 35(3/4), 113.

9. Rajendran S, Apparao B V and Palaniswamy N, Anticorrosion Methods Materials, 1998, 45(5), 338.

10. Shalaby M N and Osman M M, Anticorrosion Methods Materials, 2001, 48(5), 309.

11. Oguzie E E, Mater Chem Phy., 2004, 87, 212.

12. Ebenso E E, Mater Chem Phy., 2003, 79, 58. 


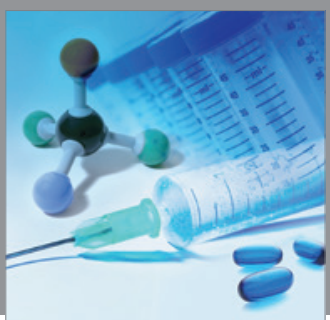

International Journal of

Medicinal Chemistry

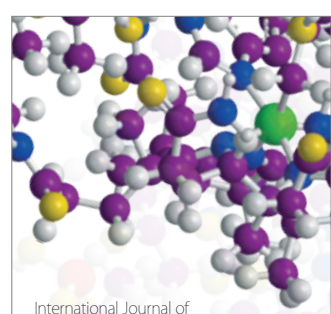

Carbohydrate Chemistry

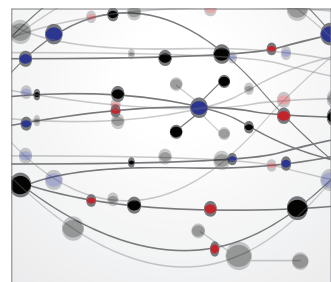

The Scientific World Journal
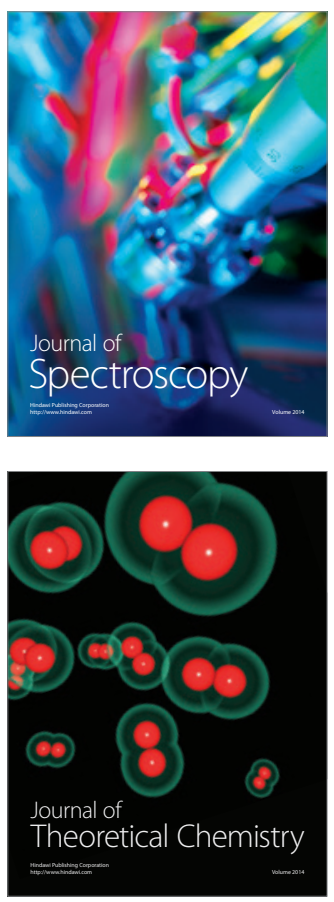
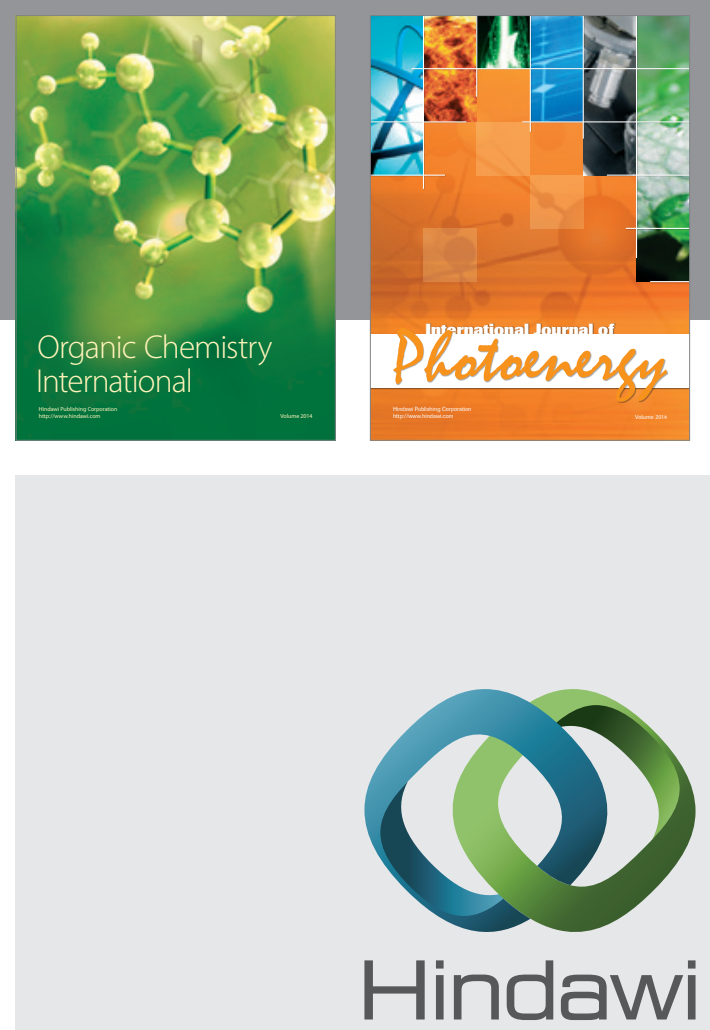

Submit your manuscripts at

http://www.hindawi.com
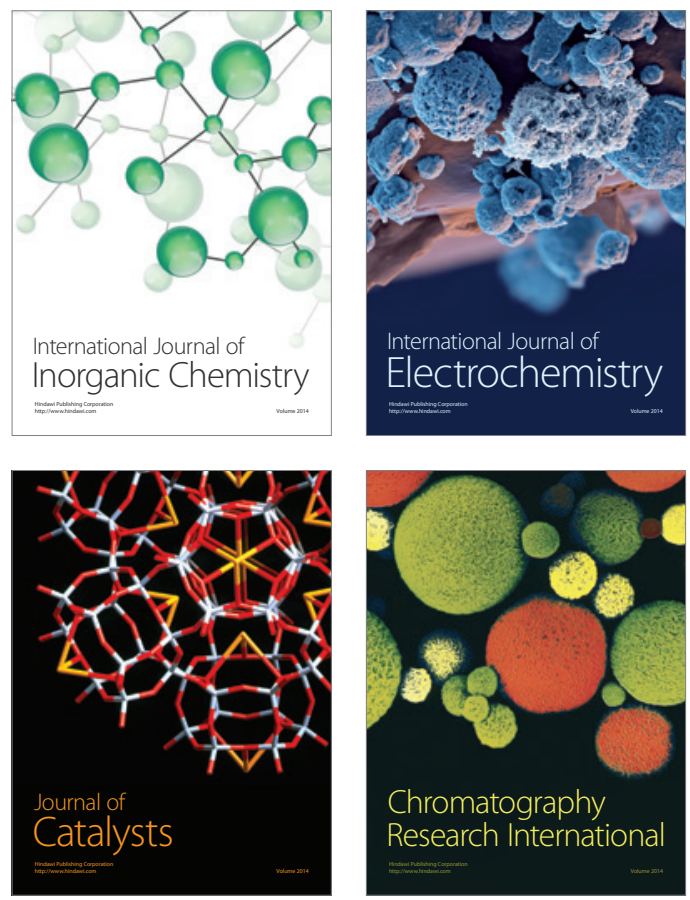
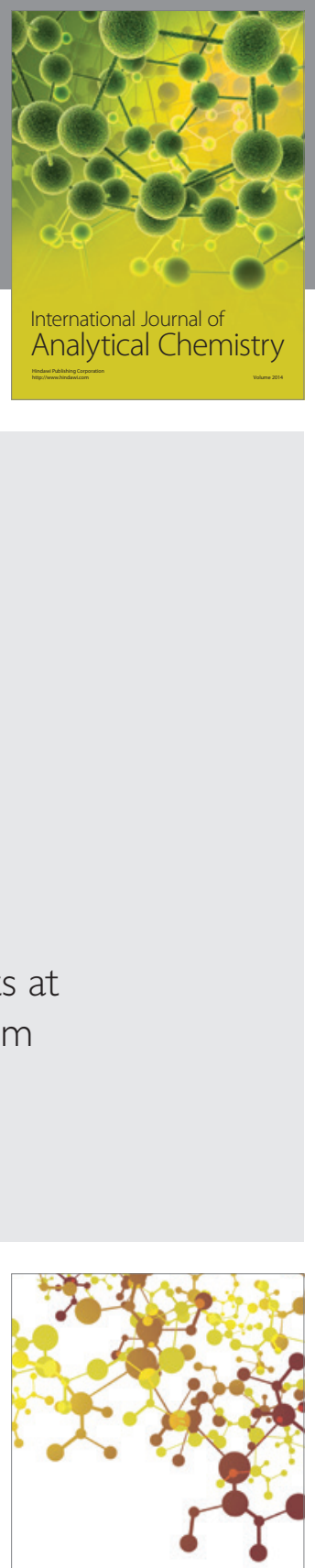

Journal of

Applied Chemistry
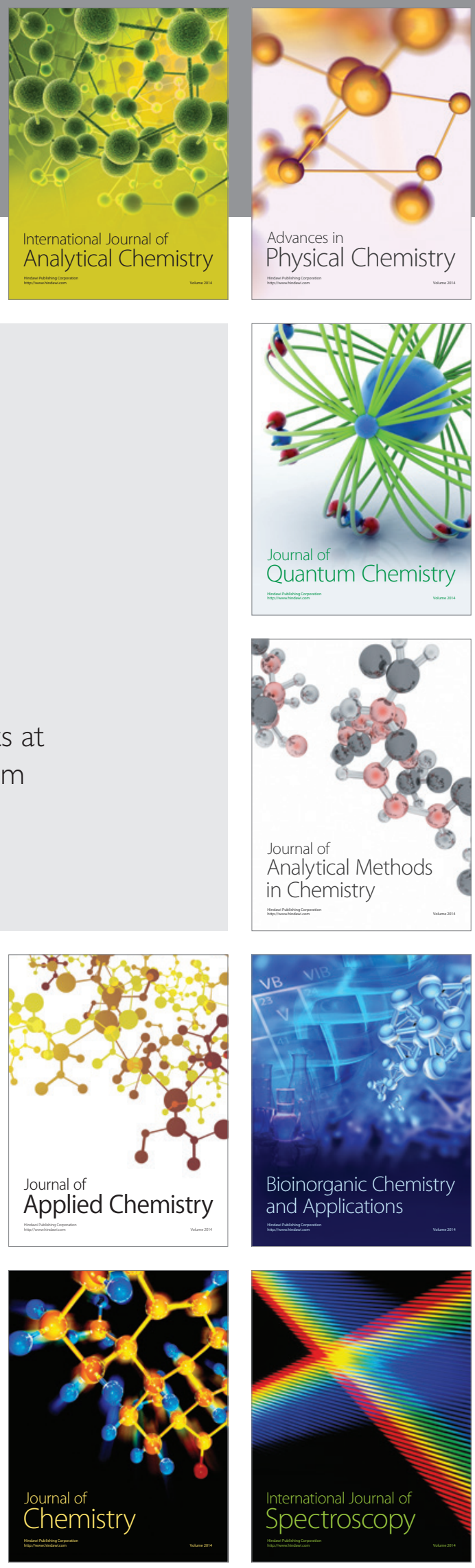